\title{
Mammalian aromatases
}

\author{
Alan Conley ${ }^{1}$ and Margaret Hinshelwood ${ }^{2}$ \\ ${ }^{1}$ Department of Population Health and Reproduction, School of Veterinary Medicine, \\ University of California, Davis, CA 95616, USA; and ${ }^{2}$ Department of Obstetrics and \\ Gynecology, University of Texas Southwestern Medical Center, Dallas, TX 75235, USA
}

\begin{abstract}
Aromatase is the enzyme complex that catalyses the synthesis of oestrogens from androgens, and therefore it has unique potential to influence the physiological balance between the sex steroid hormones. Both aromatase cytochrome P450 (P450arom) and NADPH-cytochrome P450 reductase (reductase), the two essential components of the enzyme complex, are highly conserved among mammals and vertebrates. Aromatase expression occurs in the gonads and brain, and is essential for reproductive development and fertility. Of interest are the complex mechanisms involving alternative promoter utilization that have evolved to control tissue-specific expression in these tissues. In addition, in a number of species, including humans, expression of aromatase has a broader tissue distribution, including placenta, adipose and bone. The relevance of oestrogen synthesis and possibly androgen metabolism in these peripheral sites of expression is now becoming clear from studies in P450arom knockout (ArKO) mice and from genetic defects recognized recently in both men and women. Important species differences in the physiological roles of aromatase expression are also likely to emerge, despite the highly conserved nature of the enzyme system. The identification of functionally distinct, tissue-specific isozymes of P450arom in at least one mammal, pigs, and several species of fish indicates that there are additional subtle, but physiologically significant, species-specific roles for aromatase. Comparative studies of mammalian and other vertebrate aromatases will expand understanding of the role played by this ancient enzyme system in the evolution of reproduction and the adaptive influence of oestrogen synthesis on general health and well being.
\end{abstract}

Steroids are essential components of the endocrine control of vertebrate reproduction. Normal reproductive development in mammals is critically dependent on the properly regulated biosynthesis of sex steroids. Many diseases and conditions affecting fertility and general health are accompanied by aberrations in androgen or oestrogen metabolism (Mason and Franks, 1997; Sasano and Harada, 1998). Evidence to support this contention is provided by studies of individuals suffering from genetic abnormalities affecting steroidogenic enzymes (White, 1994) or steroid receptors (Couse and Korach, 1999), as well as from studies using knockout mice. The associated clinical phenotypes include infertility and reproductive failure, accompanied by altered somatic growth, mineral metabolism (particularly calcium) and even altered cardiovascular function in some cases (Couse and Korach, 1999; Simpson, 2000). Therefore, the balance between androgen and oestrogen production is not only essential for normal sexual development and reproduction, but also for the normal growth and physiological well being of both sexes. Activity arising from the enzyme

Email: ajconley@ucdavis.edu complex known as aromatase, uniquely positioned to affect both androgen metabolism and oestrogen synthesis, has unusual potential to influence the balance of both classes of sex steroid hormone.

\section{The aromatase enzyme complex}

Ostrogens are products of androgen metabolism catalysed by the enzyme complex known as aromatase. This enzyme complex consists of two components: aromatase cytochrome P450 (P450arom) and, coupled to it, a ubiquitous flavoprotein, NADPH-cytochrome P450 reductase (reductase). P450arom is a member of the cytochrome P450 superfamily of enzymes, in a subgroup referred to as the steroid hydroxylases. Consistent with its fundamental biological importance, P450arom is highly conserved especially among mammals (Fig. 1) and all vertebrates, and demonstrates $50-90 \%$ peptide sequence identity between fish and mammalian forms of the enzyme. This degree of conservation is even more marked at the genomic level: the exon-intron boundaries are almost identical for the genes encoding P450arom in humans (Simpson et al., 1994) and 


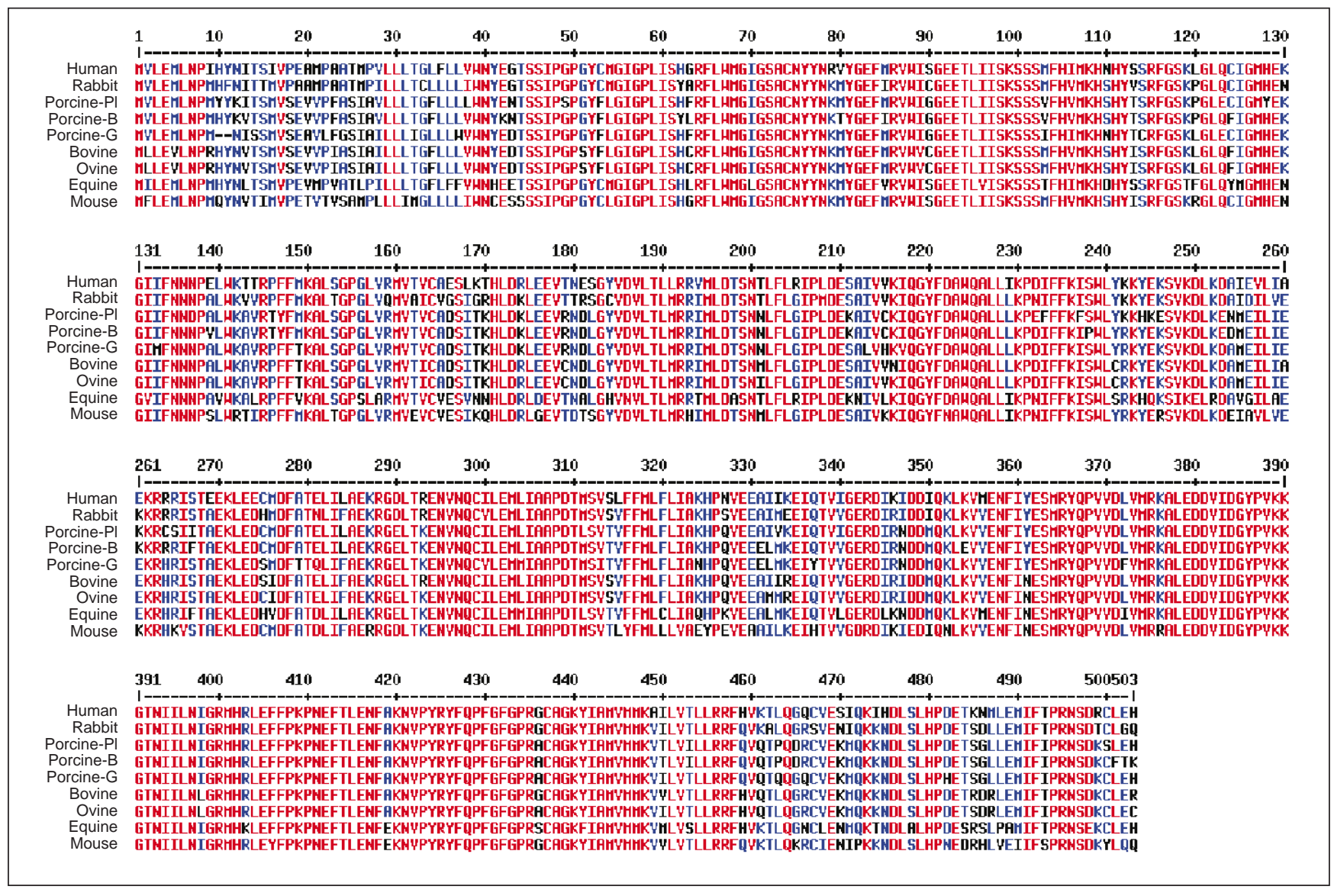

Fig. 1. Multiple peptide alignment of mammalian aromatases. The analysis was conducted using the default settings of the MultiAlin program (Corpet, 1988) available online at www.toulouse.inra.fr/multalin. Sequences were retrieved from GenBank entries via www.ncbi.nlm.nih.gov. Consensus levels are shown in colour: high (red) $=90 \%$, low (blue) $=50 \%$, neutral (black) $=<50 \%$. Although multiple entries have been made for many species, the following accession numbers will retrieve P450arom sequences for the named mammalian species: equine AAC04698, CAB38442; ovine Q9XS28; pig placenta AAB51387, P79430; pig gonadal AAB 51388, P79304; pig blastocyst Q29624; bovine I46015, S44210; mouse S13912; human O4HU19, AAA52132; rabbit Q29605.

the teleost fish medaka (Tanaka et al., 1995). These boundaries have survived despite the development of significant differences in gene size: the human CYP19 gene extends over $70 \mathrm{~kb}$, whereas the medaka CYP19 gene is only $2.6 \mathrm{~kb}$. To date, few other CYP19 genes have been cloned entirely, but partial sequence data indicate that the pig gene and other mammalian genes use the same splice sites as the human gene, even in the $5^{\prime}$-untranslated region of the transcript (Hinshelwood et al., 1995). Fewer vertebrate reductases have been cloned compared with P450arom, but this P450 redox partner protein is as ancient as the P450 enzymes it supports, and is even more highly conserved. There is greater than $90 \%$ conservation among mammalian reductases and $76 \%$ between trout and mammalian flavoproteins (Porter, 1991). Thus, on the basis of sequence analysis alone, both components of the aromatase complex (P450arom and reductase) are highly conserved, consistent with the narrow functional constraints on the enzyme complex.

\section{Aromatase reaction}

Most of what is known about the catalytic function of P450arom has been determined from studies on the human enzyme (Siiteri, 1982). Typically, cytochromes P450 incorporate molecular oxygen into substrates by reactions that are dependent on efficient electron transfer from donor molecules. However, the catalytic process leading to the aromatization of androgens is unusually complex (Fig. 2). It requires the sequential transfer of three pairs of electrons and consumes three moles of oxygen and three moles of reduced $\mathrm{NADPH}$ in the synthesis of one mole of oestrogen. The reaction is thought to involve two consecutive hydroxylations at the C19 methyl group (19-hydroxylase activity) of the steroid substrate, forming 19-hydroxy and eventually 19-oxo-intermediates. A third oxidative event, which is still debated (Akhtar et al., 1997), culminates in the cleavage of the angular C19 methyl group (19-demethylase or desmolase activity), aromatization of the steroid A ring 


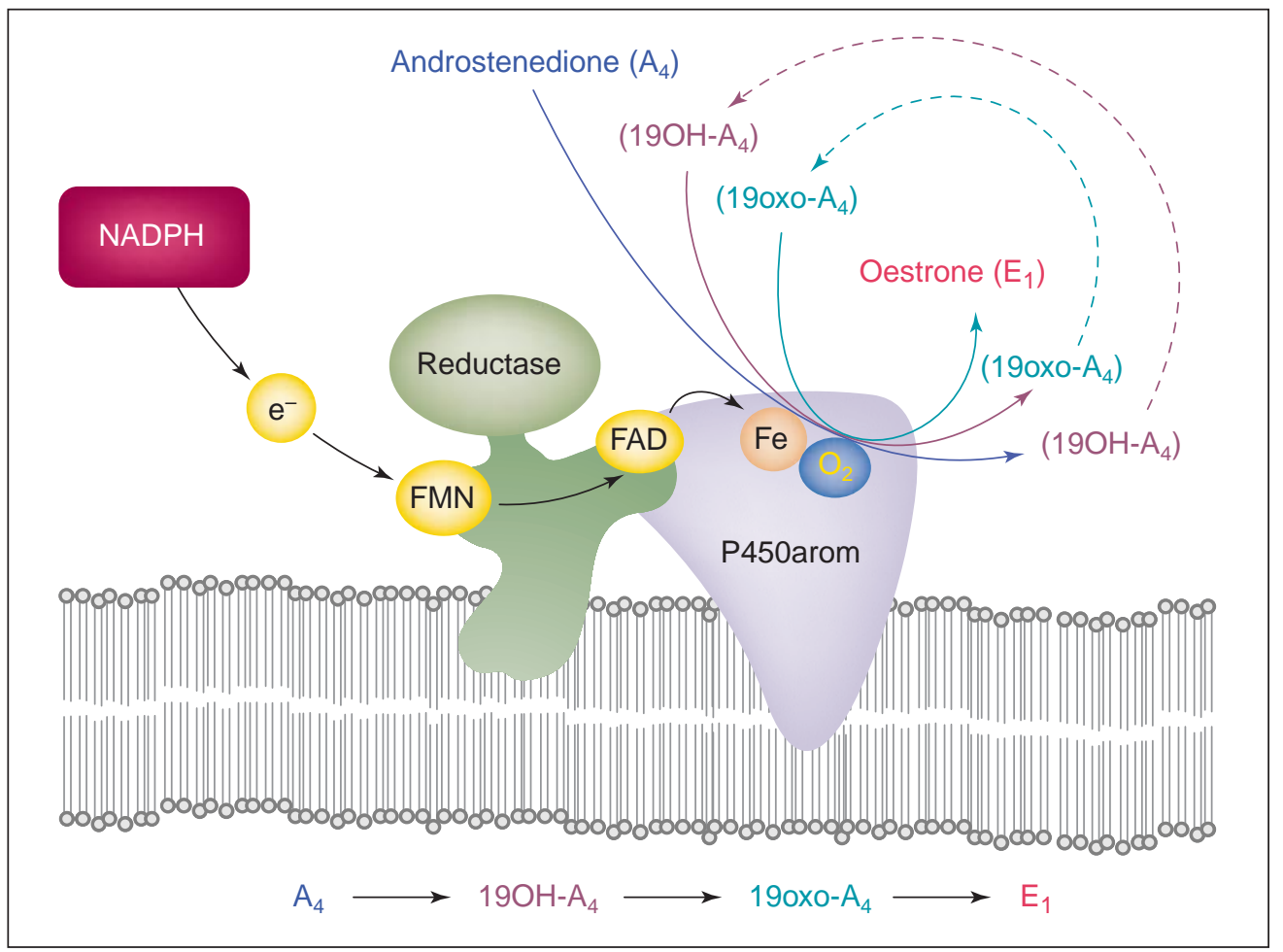

Fig. 2. Schematic diagram of the microsomal membrane anchoring the aromatase enzyme complex which consists of aromatase cytochrome P450 (P450arom) and the redox partner protein NADPHcytochrome P450 oxidoreduxtase (reductase). The flavin prosthetic groups of the reductase, flavin adenine dinucleotide (FAD) and flavin mononucleotide (FMN), are indicated. Reducing equivalents as electrons $\left(\mathrm{e}^{-}\right)$from reduced nicotinamide adenine dinucleotide phosphate (NADPH) are also shown, along with the iron $(\mathrm{Fe})$ of the co-ordinated haem and oxygen $\left(\mathrm{O}_{2}\right)$ in the substrate-binding pocket of P450arom. Note that three oxidative cycles are required to convert C19 substrates, in this case androstenedione $\left(\mathrm{A}_{4}\right)$, through its $19 \mathrm{OH}$ - and 190xo- intermediates $\left(19 \mathrm{OH}-\mathrm{A}_{4}\right.$ and $\left.190 \mathrm{oxo}-\mathrm{A}_{4}\right)$ for final oestrogen synthesis. Although intermediates are shown in parentheses, indicating transient appearance only, in many cases they may escape further metabolism and become additional reaction products. The complete aromatization reaction is shown beneath the diagram.

and oestrogen formation. Androstenedione and testosterone are the most common, well recognized and probably most physiologically important substrates. However, $16 \mathrm{OH}-$ androstenedione, arising from hepatic hydroxylation of fetal adrenal dehydroepiandrosterone sulphate (DHEAS), is an additional substrate utilized in placental oestriol synthesis during pregnancy in women and some primates (Siiteri, 1982). Furthermore, aromatization is not always complete. The intermediates $19 \mathrm{OH}$ - and 19-oxo-androstenedione and -testosterone are released during androgen metabolism by P450arom, and are additional reaction products in some cells and tissues (Corbin et al., 2000). The release of these intermediates appears to be increased when reductase expression is not adequate to saturate P450arom (Swinney et al., 1993). This situation occurs during human pregnancy, when $19 \mathrm{OH}$-androstenedione concentrations increase at a faster rate than oestrogen concentrations as pregnancy progresses (Osawa et al., 1990). It is possible that these so-called intermediates also have effects, such as the induction of hypertension (Martin et al., 1985), which may prove to be of physiological or clinical relevance. There are also reports of the biosynthesis of 19-norandrogens involving pig aromatase (Khalil et al., 1989), although the direct formation of these steroids by P450arom has not been confirmed (Corbin et al., 1999, 2000). The 19nor-steroids are effective substrates for aromatase in other species, most notably horses (Moslemi et al., 1998). In addition, P450arom shows other catalytic activities including 2-hydroxylase, which may be responsible for some catechol oestrogen formation in the human and equine placenta (Osawa et al., 1993; Almadhidi et al., 1996).

Kinetic analyses have also been conducted using mainly human placental P450arom, since the human term placenta appears to have one of the highest levels of expression of the mammalian tissues studied to date. Similar analyses have been performed on enzymes from a few animals from which P450arom has been cloned and expressed recombinantly. Estimated affinity constants $\left(K_{\mathrm{m}}\right)$ 
for androstenedione range from 1 to $100 \mathrm{nmol} \mathrm{I}^{-1}$ for the purified human placental enzyme (summarized by Yoshida and Osawa, 1991). Estimates of the $K_{\mathrm{m}}$ values for testosterone are similar or slightly higher than those for androstenedione for human (Yoshida and Osawa, 1991) and chicken P450arom (McPhaul et al., 1988), but turnover is similar. However, the pig gonadal P450arom has a higher $K_{\mathrm{m}}$ value and slower turnover rate for testosterone than does the pig placental isozyme (Corbin et al., 1999, 2000). On the basis of these data, it was suggested that placental aromatase function may have evolved from the gonadal isozyme toward more efficient testosterone metabolism. This idea is consistent with the need to protect female fetuses from androgen exposure during sexual differentiation in utero. More efficient metabolism of androstenedione is equally adaptive in the ovary. Here, there is low expression of the form of $17 \beta$-hydroxysteroid dehydrogenase (human type III) that efficiently converts androstenedione to testosterone, at least in the human preovulatory follicle (Zhang et al., 1996), which expresses predominately the type I form of the enzyme. The affinity of androstenedione for P450arom is in the nanomolar range, at least an order of magnitude higher than that of most other microsomal steroid hydroxylases, indicating that aromatization is efficient at very low substrate concentrations. This represents an important biochemical adaptation of P450arom that facilitates oestrogen synthesis in peripheral non-classical steroidogenic tissues in which androgens are not synthesized locally in high concentrations (Corbin et al., 1999).

\section{Aromatase expression}

P450arom expression is restricted to the gonads and brain in many vertebrates, from aquatic and avian species to mammals. In the ovary, the expression of P450arom is much higher in the granulosa cells of preovulatory follicles than in small follicles (Hickey et al., 1988). In some species, such as humans and rodents, P450arom can also be localized to the corpus luteum (Doody et al., 1990). In the testes, aromatase activity is found in Sertoli cells before puberty and in Leydig cells of adult male rodents (Abney, 1999). Aromatase activity and transcripts have also been observed in testicular germ cells of several species, including pachytene spermatocytes, elongating spermatids and epididymal spermatozoa (Janulis et al., 1996). Therefore, synthesis in male germ cells, along with Sertoli and Leydig cells, may be another important source of oestrogen in the male reproductive tract.

Oestrogen biosynthesis and hence P450arom expression in the brain is necessary for normal sexual behaviour. Aromatase in the brain has been studied extensively, primarily in rats (for a review, see Lephart, 1996). High aromatase activity was found in the medial basal hypothalamic area and amygdaloid regions of the male rat (Lephart, 1996). Specifically, aromatase activity was high in the amygdala, periventricular preoptic nucleus and medial preoptic nucleus and lower activity was found in the superchiasmatic nucleus, anterior hypothalamus, periventricular anterior hypothalamus, arcuate nucleus, the cortex and various other regions. These regions are important in neuroendocrine regulation of reproduction and behaviour, and in many cases display development and sexually dimorphic differences in activities of the enzyme. In rats, aromatase activity is slightly higher in males than in females. The enzyme is found in the hypothalamus of both sexes during the prenatal period, after day 16 of gestation (Lephart et al., 1992). Aromatase declines at birth and declines further after puberty. Regulation of expression of P450arom in the gonads appears to differ from that in the brain. In both the ovary and testes, the gonadotrophins FSH and $\mathrm{LH}$ act through increasing concentrations of intracellular cyclic AMP (cAMP) to induce expression of P450arom. Conversely, in the brain, agents that increase intracellular concentrations of cAMP cause a decrease in aromatase activity, whereas androgens may act to induce expression of the gene (Roselli and Resko, 1993).

In addition to P450arom expression in the gonads and brain, there is a much wider tissue distribution of the enzyme in some species. In humans, besides expression in the gonads and brain, P450arom is found in the syncytiotrophoblast of the placenta, adipose stromal cells, osteoblasts in bone, skin fibroblasts, certain portions of the vasculature, as well as in fetal liver and other fetal tissues (Simpson et al., 1994; Harada et al., 1999). As is found in gonad-specific versus brain-specific expression of P450arom, the factors and pathways that activate or inhibit expression vary widely among these tissues. This regulation occurs, in part, through the use of tissue-specific promoters and by alternative splicing mechanisms (Fig. 3), which regulate the transcription of a single sequence encoding human P450arom (Simpson et al., 1997). Expression of P450arom in human placenta is controlled primarily by a promoter that lies at least $40 \mathrm{~kb}$ upstream from the start site of translation (promoter I.1 or la; Kamat et al., 1999). In contrast, the promoter driving transcription in the ovary lies just upstream of the start site of translation (promoter II or $1 \mathrm{~d}$; Means et al., 1991). In human adipose tissue, as well as in fetal liver, the primary promoter lies about $15 \mathrm{~kb}$ upstream of the start site of translation (promoter I.4 or 1b; Mahendroo et al., 1993) and is a TATA-less promoter driven by glucorticoids and class I cytokines (Simpson and Zhao, 1996). The exact location of the brain-specific promoter (If; Honda et al., 1994) is not known, but it may lie between the adipose- and gonad-specific promoters in a gap in the gene sequence that has yet to be closed (Fig. 3). Each of these promoters lies just upstream of tissue-specific exons, which encode the $5^{\prime}$-untranslated regions of aromatase mRNAs in these tissues. These exons are alternatively spliced onto a common splice site approximately $39 \mathrm{bp}$ upstream of the codon in exon II that initiates translation, so the protein expressed in the different tissues is identical (Simpson et al., 1994). Moreover, tissue-specific expression may be directed by a sequence relatively near the transcript initiation site. 
(a)

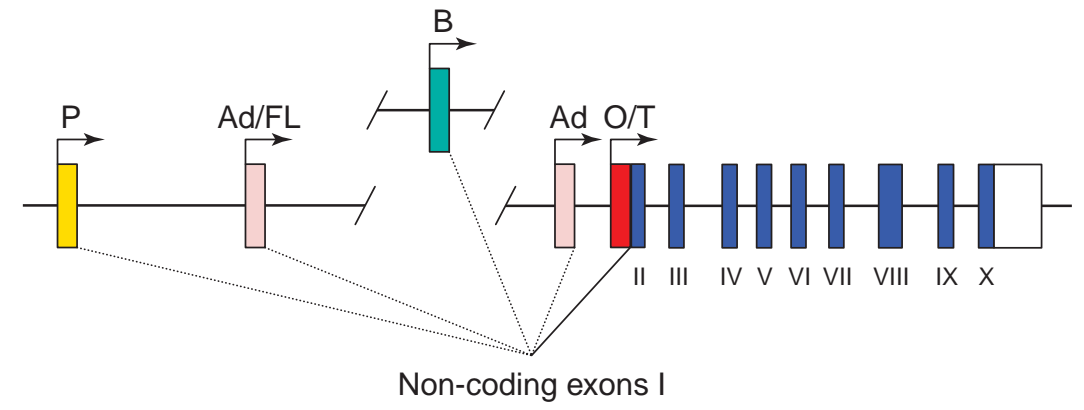

(b)

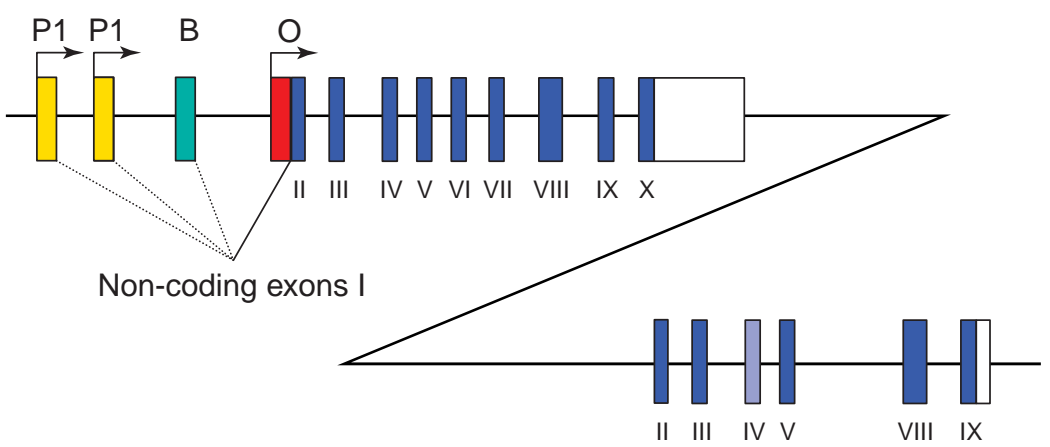

(c)

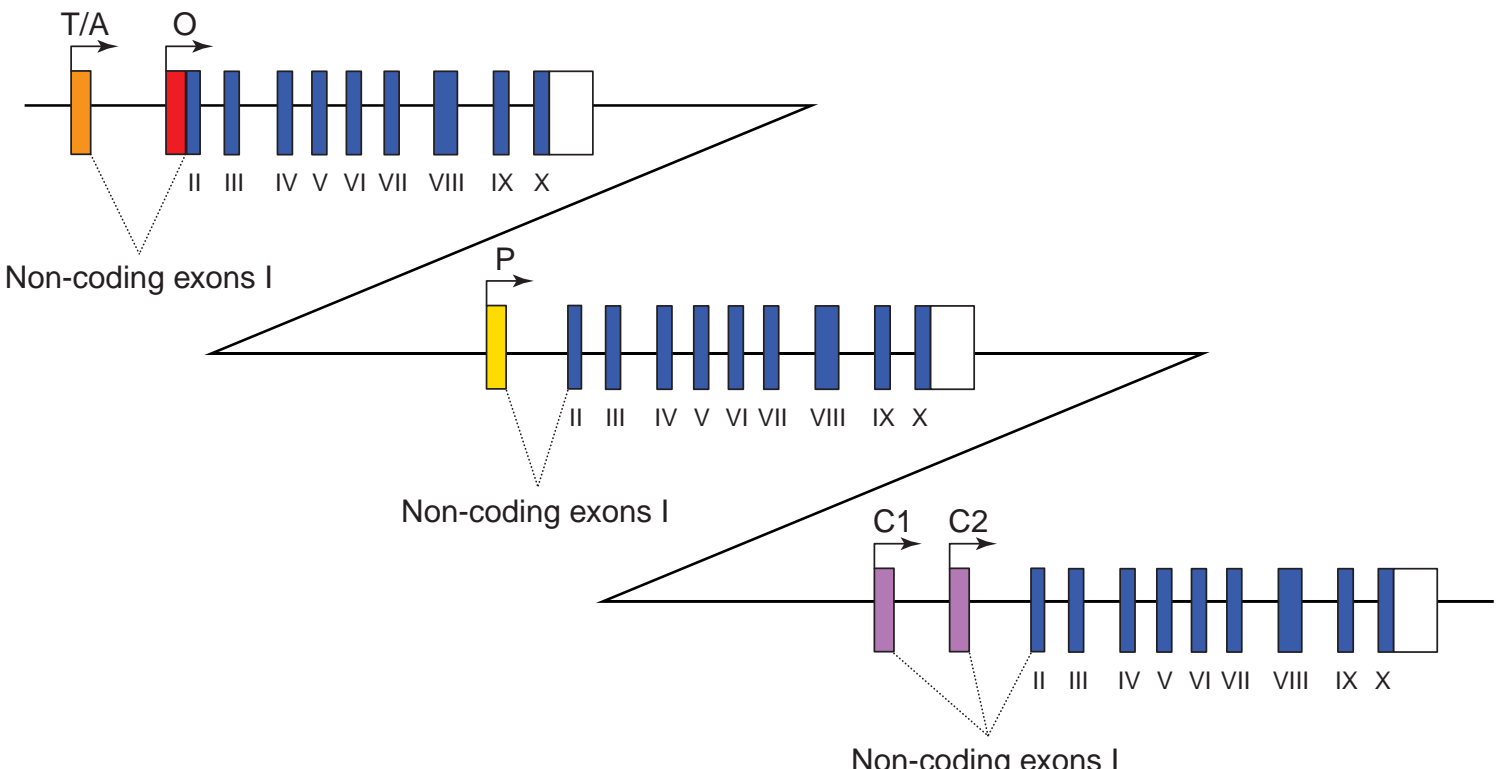

Fig. 3. Schematic diagram of the (a) human, (b) bovine and (c) pig CYP19 genes. The coding exons are represented by blue boxes and the $3^{\prime}$-untranslated regions are represented by white boxes. The coding region encompasses exons II-X. The haem binding region is present in exon X. The start site of translation is in exon II. The first exons are shown in different colours, dependent upon the tissues in which they are expressed. The arrow indicates the start site of transcription. Dashed lines indicate how these first exons are spliced onto a common acceptor site in exon II. (a) There is thought to be only one human gene. Five different first exons and promoters are shown (Simpson et al., 1997). There have been several other minor variants described. The location of the brain-specific first exon is not known, but it may be located within the gap shown, which has not been bridged. (b) The bovine gene and psuedogene are shown. Two different placentaspecific first exons and promoters have been isolated (P1 and P2), along with a brain-specific first exon and an ovary-specific first exon and promoter. The specific promoter for the pseudogene is not known, and the stippled box for exon IV for the psuedogene indicates that it is different than the exon IV in the gene (Furbass and Vanselow, 1995; Hinshelwood et al., 1995, 1997; Brunner et al., 1998). (c) There are three known genes encoding aromatases in different pig tissues, all arranged in tandem. There are two postulated conceptus-specific first exons and promoters (Corbin et al., 1995; Choi et al., 1996; Conley et al., 1997; Graddy et al., 2000). A: adrenal; Ad: adipose; B: brain; C: conceptus; FL: fetal liver; O: ovary; P: placenta; T: testes. 
Studies using transgenic mice have mapped the sequence of the human CYP19 gene required for placental-specific expression to a region of 5 '-flanking DNA within 501 bp of exon I.1 (Kamat et al., 1999). Similarly, as little as 278 bp of 5 '-flanking DNA upstream of exon II is necessary for ovaryspecific expression in transgenic mice (Hinshelwood et al., 2000). Therefore, despite the expression of P450 in various sites, which might otherwise indicate a lack of tissue specificity, the expression of P450arom is controlled very precisely in humans by the differential use of promoters.

Other species also demonstrate P450arom expression in tissues other than the gonads and brain. In primates and ungulates, P450arom expression has been found in the placenta, although the pattern of expression and oestrogen biosynthesis varies widely among these species throughout gestation. Studies in pigs have confirmed that P450arom is also expressed in the theca interna, in addition to the granulosa of preovulatory follicles, the fetal adrenal reticularis and the trophectoderm of pre-attachment blastocysts (Conley et al., 1997). Horses also show expression of P450arom in the trophectoderm of the pre-attachment blastocyst (Walters et al., 2000). The physiological significance of expression in such diverse sites remains unclear in many cases; however, in humans, more attention is being paid to P450arom expression as an important link in the aetiology of disease. Aberrant P450arom expression in tissues that do not normally have high concentrations of the enzyme is associated with many pathological conditions in humans. These conditions include gynecomastia and sexual precocity (Stratakis et al., 1998), tumours of the breast, testes, liver, adrenal cortex and uterus (Bulun et al., 1997; Sasano and Harada, 1998), and endometriosis (Zeitoun and Bulun, 1999). In all these pathological conditions, the proximal promoter used to drive P450arom expression in disease is the same one that drives expression in the gonads (Bulun et al., 1997; Sasano and Harada, 1998; Zeitoun and Bulun, 1999). In some instances this involves 'promoter switching', such as in carcinomas of the breast. Transcripts from normal breast tissue primarily contain the untranslated (UTR) exon I.4. However, breast tissue obtained from patients with breast cancer has transcripts that primarily contain 5' UTRs with a sequence that lies immediately upstream of exon II (Fig. 3), consistent with the use of promoter II or a variant of this exon (exon 1.3 or 1c; Bulun et al., 1997; Sasano and Harada, 1998). Understanding what turns 'on' the expression of aromatase in disease or what causes a 'switch' in promoter usage is currently an area of intense investigation. Although analogous disease has not yet been identified in animals, the unusual feathered phenotype known as 'henny-feathering' of Sebright Bantam and Golden Campine roosters is associated with overexpression of P450arom in skin (Matsumine et al., 1991). Thus, strict control over tissue-specific expression is necessary for proper regulation of oestrogen synthesis which, if disrupted, can lead to aberrant phenotypes or disease.

\section{Defects in the CYP19 gene}

Studies of patients diagnosed with defects in the CYP19 gene (Simpson et al., 1997; Simpson, 2000) together with information accruing on the aromatase knockout (ArKO) strain of mouse (Fisher et al., 1998; Honda et al., 1998) have added considerably to understanding of the importance of P450arom function in both sexes. The first recognized cases of complete P450arom deficiency in women presented with genital ambiguity and subsequently hypergonadotropic hypogonadism in adolescence (Simpson et al., 1997). Virilization of the female fetus in utero is assumed to result from inadequate aromatization of androgens derived from fetal adrenal C19 steroids, emphasizing the immediate importance of P450arom in androgen metabolism. Ovarian cystic degeneration, which has been observed later in life, is consistent with an essential role for oestrogen in normal ovarian function if not development. An analogous state of ovarian cystic degeneration, characterized by a lack of follicular development and ovulation, has also been noted in the ArKO strain of mice lacking P450arom expression (Britt et al., 2000). In addition, the importance of oestrogen in male development and reproductive function has been highlighted by the identification in men and male mice of genetic defects that involve disrupted P450arom expression (Carani et al., 1997). In general, the phenotypes observed correspond reasonably well to those resulting from oestrogen receptordeficient states. Lack of P450arom expression in male ArKO mice is associated with testicular degeneration (Carani et al., 1997; Robertson et al., 1999) and in men with a failure of epiphyseal closure leading to abnormal long bone growth with osteopaenia (Morishima et al., 1995; Carani et al., 1997). Serum gonadotrophin concentrations are increased, although androgens are more variable and concentrations may be normal or high. Continued evaluation of the similarities in phenotype shared by oestrogen receptor and CYP19 defects will no doubt lead to a better understanding of P450arom and oestrogen function.

However, there are some notable differences between oestrogen receptor- and aromatase-deficient states, and the apparent resulting phenotype in men and mice. Testicular degeneration in the oestrogen receptor knockout (ErKO) mouse appears before puberty and is associated with excessive fluid accumulation in the seminiferous tubules (Couse and Korach, 1999). No similar lesion is seen in ArKO mice, instead spermatogenesis is disrupted for between 4.5 months and 1 year, without consistently altered gonadotrophin or androgen concentrations. Spermatogenesis appears to be arrested primarily at early spermiogenic stages, and is characterized by an increase in apoptosis and the appearance of multinucleated cells. Fewer round and elongated spermatids were reported, but no changes in Sertoli cells or earlier germ cells were noted (Robertson et al., 1999). In addition, poor libido has been observed among ArKO male mice (Honda et al., 1998), as in ErKO mice, but poor libido is not a consistent finding in either 
aromatase deficiency or oestrogen receptor defects in men (Morishima et al., 1995; Carani et al., 1997; Couse and Korach, 1999). Different results, depending on gender, were also obtained in ArKO mice in cases of oestrogen effects on bones (Oz et al., 2000). Both ArKO males and females demonstrated osteoporosis, characterized by significant decreases in trabecular bone volume and trabecular thickness. However, compared with the wild-type littermates, female ArKO mice showed increased bone turnover, similar to early postmenopausal osteoporosis in humans. Conversely, male ArKO animals showed decreases in both osteoblastic and osteoclastic surfaces compared with wild-type littermates, similar to age-related osteopaenia. These findings indicate that osteoporosis in aromatase-deficient mice may arise from different bone remodelling activities between males and females. The extent to which these reproductive and other phenotypes reflect mouse strain or species variation, or even differences in the degree of physiological compensation that is possible (for example signalling through oestrogen receptor $\beta$ or even nonoestrogen receptor linked pathways), is unclear at present.

Although it is probable that, in the case of the ArKO and ErKO strains, the resulting phenotype is due exclusively to oestrogen deprivation, the effect of increased local tissue androgen concentrations cannot be ruled out. Even if circulating concentrations are not consistently high, a lack of local androgen metabolism might complicate the character of the resulting degenerative processes. In addition, it is not possible to divorce insipid effects of gene knockouts on development from those on function at maturity after normal development. The pharmacological inhibition of aromatase activity has been studied in at least one primate species (Shetty et al., 1997). Treatment of sexually mature female bonnet monkeys with aromatase inhibitors induced significant increases in FSH and androstenedione concentrations, but depressed serum oestradiol concentrations, inhibited the preovulatory LH surge and prevented ovulation. Treatment did not preclude follicular maturation (an increase in the number of follicles was observed) or an effective ovulatory response to exogenous gonadotrophin, but no pregnancies resulted from supposedly fertile matings. Aromatase inhibition in male bonnet monkeys induced a sustained five- to tenfold increase in serum testosterone, but a decrease in sperm maturation and semen quality. These results in a primate species do not fit exactly the clinical picture of human CYP19 defects, or those of ArKO mice. Therefore, congenital aromatase deficiency in humans and in mouse models must be interpreted cautiously, especially when making inferences about the immediate role of P450arom in reproductive function and fertility that follows normal developmental pathways.

However, as noted earlier, the proper balance of exposure to androgens and oestrogens affects many physiological or pathological processes in subtle ways that are only now being recognized. This realization is consistent with the expression of P450arom in cells from numerous tissues. Adipose tissue is the possibly the best example, since this is the major site of oestrogen formation in men and postmenopausal women (Siiteri, 1982). The peripheral aromatization of adrenally derived androgens may be a particularly important factor in development of disease later in life. Oestrogen also has profound effects on calcium metabolism, and remains a common therapy for the prevention of osteoporosis in women after the menopause. In addition, studies have demonstrated that P450arom expression is correlated with the incidence of neoplasia in certain quadrants of the human breast (Simpson et al., 1994; Sasano and Harada, 1998). On the basis of known oestrogen-dependent growth characteristics of certain mammary carcinomas, it seems reasonable that stromal expression of P450arom predisposes to the onset of this cancer (Simpson and Zhao, 1996). Therefore, although P450arom expression in adipose tissue may mitigate against osteoporosis in the elderly, in certain other peripheral sites of expression, it may increase the likelihood of disease.

\section{CYP19 gene structure}

As described earlier for the human gene, most studies conducted to date into the genes encoding P450arom in mammals have indicated that the enzyme is encoded by a single gene. Although there may be multiple first exons that are involved in tissue-specific expression, these exons are untranslated in most species (Fig. 3). Therefore, P450arom expressed in different tissues represents only one protein with one amino acid sequence. Owing to the evolutionary pressure on P450arom as an enzyme essential for successful reproduction of a species, conservation of the gene at this level would be expected. This proposal is supported by a comparison of the promoters and untranslated exons responsible for tissue-specific expression, which reveal a high degree of sequence conservation among species. Conservation is particularly evident in the gonad- and brain-specific first exons and promoters, for which the cDNAs and genes from numerous aquatic, some avian and many mammalian species have been cloned. The common origin of gonadal transcripts in the genomic region contiguous with the first coding exon (II) in all these species (Hinshelwood et al., 1997) is thought to reflect the ancestral origins of gene expression in gonadal tissues. However, this proposal does not explain the evolution of the brain-specific first exon and promoter, which is highly conserved among humans, mice and horses (Boerboom et al., 1999), yet is upstream of the gonad-specific first exon and promoter. Thus, on the basis of current knowledge of the relatively few species investigated to date, mammalian CYP19 appears to involve regulation of tissue-specific expression by multiple alternative promoters that drive expression of a single coding sequence.

The evolution of placental expression of aromatase also warrants attention. Species such as humans and non-human 
primates, ungulates and rabbits, in which aromatase is expressed in the placenta, have one feature in common, a first exon and promoter that lie very far upstream of the start site of translation (Fig. 3). In the human CYP19 gene, this placenta-specific first exon is approximately $40 \mathrm{~kb}$ upstream of the start site of translation (Kamat et al., 1999), whereas in the bovine CYP19 gene, it is approximately $19 \mathrm{~kb}$ upstream (Hinshelwood et al., 1995; Brunner et al., 1998). However, comparison of the human, bovine, equine and pig sequences revealed very little sequence identity among many of these placenta-specific first exons (Hinshelwood et al., 1995). Correspondingly, the general usage of an alternative distal untranslated first exon in the placenta is taken as evidence of the later evolution of the placenta and of placental P450arom expression in vertebrates. This proposal implies that placental expression was achieved through a convergence, rather than a divergence, of evolution, which might be expected from the differences in placental morphology, even among the four species mentioned above.

In addition to the observations regarding placentaspecific expression of P450arom, studies on the CYP19 gene in pigs also provided unexpected results. The pig is the first vertebrate identified to have duplicated entire functional copies of P450arom in its genome (Corbin et al., 1995; Graddy et al., 2000) and remains unique among mammals in this regard (Fig. 3). These genes appear to be clustered in a discrete region on chromosome 1 . However, each gene has evolved or accumulated exonic differences that result in a number of amino acid changes in the P450arom protein depending upon the tissue in which it is expressed (Graddy et al., 2000). To date, three different transcripts encoding distinct isozymes of pig P450arom have been cloned, which include a gonadal (Corbin et al., 1995), a placental (Corbin et al., 1995; Choi et al., 1996) and a trophoblastic isozyme (Choi et al., 1996). Reports of a P450arom pseudogene in cattle (Furbass and Vanselow, 1995) indicate that gene duplication may have occurred in other mammals, but that the mutations either precluded a functional protein or resulted in a functional gene that subsequently became redundant. Several fish species have duplicate CYP19 genes, each encoding a slightly different protein, with a different promoter and region of 5 '-flanking DNA (Tchoudakova and Callard, 1998). One gene appears specific for P450arom expression in the gonads, whereas the other is specific for P450arom expression in the brain. However, the pig remains the only mammal known to expresses distinct tissue-specific isozymes of P450arom by way of multiple genes.

The physiological significance of the multiple P450arom genes in pigs is unknown at present. However, it is possible that the catalytic efficiency of the P450arom isozyme encoded by each duplicate gene differs from that of the others. The placental and trophoblastic isoforms are each 503 amino acid proteins (as are human, bovine and equine P450arom) and appear to share greater homology with one another than either does with the pig gonadal isozyme
(Fig. 1), which contains only 501 amino acids (Conley et al., 1997). A six base pair deletion results in two amino acids missing in the extreme $\mathrm{N}$-terminus of the enzyme (Corbin et al., 1995). Evidence also indicates that the gonadal isozyme is far less catalytically active than that expressed in the pig placenta (Corbin et al., 1999). However, the transcript expressed in the ovary shares the same high homology in the $5^{\prime}$ region of the sequence with the ovarian P450arom transcripts from human, bovine and equine species (Hinshelwood et al., 1995). This finding indicates that pig ovarian P450arom also evolved first, that is, it is probably ancestral to the others. These data, together with the possibility of a bovine pseudogene (Fig. 3), are consistent with the notion that other species may have evolved a single functional gene by the elimination of other less adapted duplicate CYP19 genes. Further studies in other mammals are needed to explore such a possibility.

\section{Subcellular and cellular distribution of aromatase}

Both P450arom and reductase are thought to reside in the microsomal environment of the endoplasmic reticulum (Fig. 2 ), as determined by differential centrifugation (Corbin et al., 2000) and immunochemical techniques (FournetDulguerov et al., 1987). However, earlier reports indicated that human placental P450arom might be associated with both the mitochondrial and microsomal compartments. Amarneh and Simpson (1996) reported that P450arom and reductase as well as $17 \alpha$-hydroxylase cytochrome P450 (P450c17), the enzyme responsible for androgen synthesis and the supply of substrate for P450arom, were associated with the plasma membrane of cell lines expressing recombinant enzymes. The plasma membrane is another subcellular fraction that routinely shows significant aromatase activity. The traditional view certainly holds that some enzymes are located in the microsomal compartment, some in the mitochondria and others in the cytosol. This view necessitates the shunting of steroid substrates and intermediates, sometimes back and forth, between subcellular compartments. However, this interpretation has been challenged and it has been suggested that enzymes may form functional complexes that overcome an otherwise strict microsomal or mitochondrial membrane association (Lieberman and Prasad, 1990). The well known effects of cell shape on steroidogenesis also imply functional organization that is coupled to cellular micro- and intermediate filaments (Hall, 1995). The rapid disappearance of both P450arom and P450c17 from the trophectoderm upon elongation of the pig pre-attachment blastocyst might be additional evidence to support this hypothesis (Conley et al., 1997).

Whatever their subcellular location, both P450arom and $\mathrm{P} 450 \mathrm{c} 17$ require reductase as the redox protein for complex formation, electron transfer and enzyme activity. If expressed in the same cell, these two steroid hydroxylases potentially compete with one another for reductase binding, reducing equivalents and $\mathrm{O}_{2}$. In general, steroidogenesis is an interdependent series of metabolic pathways, but the 
relationship between androgens and oestrogens is particularly intimate since oestrogen synthesis is totally dependent on androgen substrate supply (Gore-Langton and Armstrong, 1994). This dependence indicates the need for co-ordinated regulation of the enzymes catalysing the synthesis of androgens and oestrogens for oestrogen synthesis to be efficient. Consistent with this idea, evidence from studies on ovarian follicular tissues from several species indicates that P450arom expression is tightly correlated with the expression of P450c17 and therefore androgen synthesis (Fortune, 1994; Boerboom et al., 1999). The greatest degree of co-ordination might be achieved by expressing all the necessary enzymes in a single steroidogenic cell that responds to a single physiological cue by upregulating expression of all requisite enzymes. However, under most circumstances in which oestrogens are synthesized in large amounts, androgen substrates are synthesized in a different cell or even a different tissue. The 'two-cell theory' of steroidogenesis has been described in the ovarian follicle in which androgens synthesized in the theca interna, which expresses P450c17, are metabolized to oestrogen in the stratum granulosum, which expresses P450arom (Hillier et al., 1994). There is similar cellular partitioning of P450arom and P450c17 expression in the primate corpus luteum (Sanders and Stouffer, 1997). Relative to the testes, the normal ovary secretes low concentrations of testosterone and other bioactive androgens. Therefore, there is little need to regulate C19 steroid production independent of oestrogen synthesis in the follicle. Another example of compartmental separation of androgen and oestrogen synthesis is seen during pregnancy, the so-called fetoplacental unit. In this case, fetal adrenal androgens are metabolized to oestrogens in the placenta. There are similar examples in other animal species, for example when androgens produced by the fetal gonads are aromatized in the equine placenta, or placental androgens are aromatized in maternal ovaries of the rat in late gestation (Hickey et al., 1988). As noted above, the high affinity of P450arom for androgen substrates may facilitate the utilization of androgens circulating in relatively low concentrations. The reason why androgen and oestrogen synthesis is partitioned into different cellular or tissue compartments remains unclear, but such partitioning may represent an unknown adaptive constraint on enzyme function which might be evident from studies on ancestral isozymes.

In summary, P450arom is a unique member of the cytochrome P450 superfamily. By way of catalytic function, the activity of this enzyme can have both subtle and profound effects on reproduction and general health. It is apparent also, if only from gene structure, that P450arom has evolved under certain biochemical constraints, subserving physiological needs that may differ across species and possibly even between breeds (Hunter et al., 1994). Therefore, it is imperative that comparative studies are conducted to elucidate the seemingly broadening biological roles of this important enzyme.
The authors wish to take the opportunity to thank their mentors and colleagues for their help, inspiration and advice over the years. They also wish to acknowledge the editorial constraints that prevented presentation of an inclusive citation list. Comprehensive reviews and more recent primary papers have been cited in most instances instead, but the authors believe that they provide a reasonable path to the many references that they were unable to include on specific topics.

\section{References}

Key references are identified by asterisks.

Abney T (1999) The potential roles of estrogen in regulating Leydig cell development and function: a review Steroids 64 610-617

Akhtar M, Lee-Robichaud P, Akhtar ME and Wright JN (1997) The impact of aromatase mechanism on other P450s Journal of Steroid Biochemistry and Molecular Biology 61 127-132

Almadhidi J, Moslemi S, Drosdowsky MA and Seralini G-E (1996) Equine cytochrome $\mathrm{P} 450$ aromatase exhibits an estrogen 2-hydroxylase activity in vitro. Journal of Steroid Biochemistry and Molecular Biology 59 55-61

Amarneh BA and Simpson ER (1996) Detection of aromatase cytochrome $\mathrm{P} 450,17 \alpha$-hydroxylase cytochrome $\mathrm{P} 450$ and NADPH:P450 reductase on the surface of cells in which they are expressed Molecular and Cellular Endocrinology 119 69-74

Boerboom D, Kerban A and Sirois J (1999) Dual regulation of promoter IIand promoter $1 \mathrm{f}$-derived cytochrome P450 aromatase transcripts in equine granulosa cells during human chorionic gonadotropin-induced ovulation: a novel model for the study of aromatase promoter switching Endocrinology 140 4133-4141

Britt KL, Drummond AE, Cox VA, Dyson M, Wreford NG, Jones MEE, Simpson ER and Findlay JK (2000) An age-related ovarian phenotype in mice with targeted disruption of Cyp 19 (aromatase) gene Endocrinology $1412614-2623$

Brunner RM, Goldammer T, Furbass R, Vanselow J and Schwerin M (1998) Genomic organization of the bovine aromatase encoding gene and a homologous pseudogene as revealed by DNA fiber FISH Cytogenetics and Cell Genetics 82 37-40

*Bulun SE, Noble LS, Takayama K et al. (1997) Endocrine disorders associated with inappropriately high aromatase expression Journal of Steroid Biochemistry and Molecular Biology 61 133-139

Carani C, Qin K, Simoni M, Faustini-Fustini M, Serpente S, Boyd J, Korach KS and Simpson ER (1997) Effect of testosterone and estradiol in a man with aromatase deficiency New England Journal of Medicine 337 91-95

Choi I, Simmen RCM and Simmen FA (1996) Molecular cloning of cytochrome P450 aromatase complementary deoxyribonucleic acid from preimplantation porcine and equine blastocysts identifies multiple novel 5 '-untranslated exons expressed in embryos, endometrium and placenta Endocrinology 1371457-1467

Conley AJ, Corbin CJ, Smith T, Hinshelwood MM, Liu Z and Simpson ER (1997) Porcine aromatases: studies on tissue-specific, functionally distinct isozymes from a single gene? Journal of Steroid Biochemistry and Molecular Biology 61 407-413

Corbin CJ, Khalil MW and Conley AJ (1995) Functional ovarian and placental isoforms of porcine aromatase Molecular and Cellular Endocrinology 113 29-37

*Corbin CJ, Trant JM, Walters KW and Conley AJ (1999) Changes in testosterone metabolism associated with the evolution of placental and gonadal isozymes of porcine aromatase cytochrome P450 Endocrinology 140 5202-5210

Corbin CJ, Trant JM and Conley AJ (2000) Porcine gonadal and placental isozymes of aromatase cytochrome P450: sub-cellular distribution and support by NADPH-cytochrome P450 reductase Molecular and Cellular Endocrinology 172 115-124

Corpet F (1988) Multiple sequence alignment with hierarchical clustering Nucleic Acids Research $1610881-10890$

*Couse JF and Korach KS (1999) Estrogen receptor null mice: what have we learned and where will it lead us? Endocrine Reviews 20 358-417 
Doody KJ, Lorence MD, Mason JI and Simpson ER (1990) Expression of ribonucleic acid species encoding steroidogenic enzymes in human follicles and corpora lutea throughout the menstrual cycle Journal of Clinical Endocrinology and Metabolism 70 1041-1045

* Fisher CR, Graves KH, Parlow AF and Simpson ER (1998) Characterization of mice deficient in aromatase (ArKO) because of targeted disruption of the cyp19 gene Proceedings National Academy of Sciences USA 95 6965-6970

Fortune JE (1994) Ovarian follicular growth and development in mammals Biology of Reproduction $\mathbf{5 0} 225-232$

Fournet-Dulguerov N, MacLusky NJ, Leranth CZ, Todd R, Mendelson CR, Simpson ER and Naftolin F (1987) Immunocytochemical localization of aromatase cytochrome $\mathrm{P} 450$ and estradiol dehydrogenase in the syncytiotrophoblast of the human placenta Journal of Clinical Endocrinology and Metabolism 65 757-763

Furbass R and Vanselow J (1995) An aromatase pseudogene is transcribed in the bovine placenta Gene 154 287-291

Gore-Langton RE and Armstrong DT (1994) Follicular steroidogenesis and its control. In The Physiology of Reproduction pp 571-628 Eds E Knobil and JD Neill. Raven Press, NY

Graddy LG, Kowalski AA, Simmen FA, Davis SL, Baumgartner WW and Simmen RC (2000) Multiple isoforms of porcine aromatase are encoded by three distinct genes Journal of Steroid Biochemistry and Molecular Biology 73 49-57

Hall PF (1995) The roles of microfilaments and intermediate filaments in the regulation of steroid synthesis Journal of Steroid Biochemistry and Molecular Biology 55 601-605

Harada N, Sasano H, Murakami H, Ohkuma T, Nagura H and Takagi Y (1999) Localized expression of aromatase in human vascular tissues Circulation Research 84 1285-1291

Hickey GJ, Chen SA, Besman MJ, Shively JE, Hall PF, Gaddy-Kurten D and Richards JS (1988) Hormonal regulation, tissue distribution and content of aromatase cytochrome P450 messenger ribonucleic acid and enzyme in rat ovarian follicles and corpora lutea: relationship to estradiol biosynthesis Endocrinology 122 1426-1436

Hillier SG, Whitelaw PF and Smyth CD (1994) Follicular oestrogen synthesis: the 'two-cell, two-gonadotropin' model revisited Molecular and Cellular Endocrinology 100 51-54

Hinshelwood MM, Liu Z, Conley AJ and Simpson ER (1995) Demonstration of tissue-specific promoters in non-primate species which express aromatase P450 (P450arom) in placentae Biology of Reproduction 53 $1151-1159$

Hinshelwood MM, Michael MD and Simpson ER (1997) The 5'-flanking region of the ovarian promoter of the bovine CYP19 gene contains a deletion in a cyclic adenosine $3^{\prime}, 5^{\prime}$-monophosphate-like responsive sequence Endocrinology 138 3704-3710

Hinshelwood MM, Smith ME, Murry BA and Mendelson CR (2000) A 278 bp region just upstream of the human CYP19 (aromatase) gene mediates ovary-specific expression in transgenic mice Endocrinology 141 2050-2053

Honda S, Harada N and Takagi Y (1994) Novel exon 1 of the aromatase gene specific for aromatase transcripts in human brain Biochemical and Biophysical Research Communications 198 1153-1160

Honda S, Harada N, Ito S, Takagi Y and Maeda S (1998) Disruption of sexual behavior in male aromatase-deficient mice lacking exons 1 and 2 of the cyp19 gene Biochemical and Biophysical Research Communications $252445-449$

Hunter MG, Biggs C, Pickard AR and Faillace LS (1994) Differences in follicular aromatase activity between Meishan and Large-White hybrid gilts Journal of Reproduction and Fertility 101 139-144

Janulis L, Hess RA, Bunick D, Nitta H, Janssen S, Asawa $\mathrm{Y}$ and Bahr JM (1996) Mouse epididymal sperm contain active P450 aromatase which decreases as sperm traverse the epididymis Journal of Andrology $\mathbf{1 7}$ $111-116$

Kamat A, Graves KH, Smith ME, Richardson JA and Mendelson CR (1999) A 500-bp region, approximately $40 \mathrm{~kb}$ upstream of the human CYP19 (aromatase) gene, mediates placenta-specific expression in transgenic mice Proceedings National Academy of Sciences USA 96 4575-4580

Khalil MW, Morley P, Glasier MA, Armstrong DT and Lang T (1989)
Formation of 4-oestrene-3,17-dione (19-norandrostenedione) by porcine granulosa cells in vitro is inhibited by the aromatase inhibitor 4-hydroxyandrostenedione and the cytochrome P-450 inhibitors aminoglutethamide and ketoconazole Journal of Endocrinology 120 251-260

* Lephart ED (1996) A review of brain aromatase cytochrome P450 Brain Research Reviews 22 1-26

Lephart ED, Simpson ER, McPhaul MJ, Kilgore MW, Wilson JD and Ojeda SR (1992) Brain aromatase cytochrome P450 messenger RNA levels and enzyme activity during prenatal and perinatal development in the rat Molecular Brain Research 16 187-192

Lieberman S and Prasad VV (1990) Heterodox notions on pathways of steroidogenesis Endocrine Reviews 11 469-493

McPhaul MJ, Noble JF, Simpson ER, Mendelson CR and Wilson JD (1988) The expression of a functional cDNA encoding the chicken cytochrome P450arom (aromatase) that catalyses the formation of estrogen from androgen Journal of Biological Chemistry 263 16 358-16 363

Mahendroo MS, Mendelson CR and Simpson ER (1993) Tissue-specific and hormonally controlled alternative promoters regulate aromatase cytochrome P450 gene expression in human adipose tissue Journal of Biological Chemistry 268 19 463-19 470

Martin JD, Hahnel ME and Hahnel R (1985) 19-Hydroxyandrostenedione - a factor in pregnancy hypertension Clinical and Experimental Hypertension B4 127-139

Mason H and Franks S (1997) Local control of ovarian steroidogenesis Bailliere's Clinical Obstetrics and Gynaecology 11 261-280

Matsumine H, Herbst MA, Ou SH, Wilson JD and McPhaul MJ (1991) Aromatase mRNA in the extragonadal tissues of chickens with the henny-feathering trait is derived from a distinctive promoter structure that contains a segment of a retroviral long terminal repeat. Functional organization of the Sebright, Leghorn, and Campine aromatase genes Journal of Biological Chemistry 266 19 900-19 907

Means GD, Kilgore MW, Mahendroo MS, Mendelson CR and Simpson ER (1991) Tissue-specific promoters regulate aromatase cytochrome P450 gene expression in human ovary and fetal tissues Molecular Endocrinology 5 2005-2013

Morishima A, Grumbach MM, Simpson ER, Fisher C and Qin K (1995) Aromatase deficiency in male and female siblings caused by a novel mutation and the physiological role of estrogens Journal of Clinical Endocrinology and Metabolism 80 3689-3698

Moslemi S, Auvray P, Sourdaine P, Drosdowsky MA and Seralini G-E (1998) Structure-function relationships for equine and human aromatases Annals of the New York Academy of Sciences 839 576-577

Osawa Y, Ohnishi S, Yarborough C, Ohigashi S, Kosaki T, Hashino M, Yanaihara T and Nakayama T (1990) Serum level of 19-hydroxyandrostenedione during pregnancy and at delivery determined by gas chromatography/mass spectrometry Steroids 55 165-169

Osawa Y, Higashiyama T, Shimizu Y and Yarborough C (1993) Multiple functions of aromatase and the active site structure; aromatase is the placental estrogen 2-hydroxylase Journal of Steroid Biochemistry and Molecular Biology 44 469-480

Oz OK, Zerwekh JE, Fisher C, Graves K, Nanu L, Millsaps R and Simpson ER (2000) Bone has a sexually dimorphic response to aromatase deficiency Journal of Bone and Mineral Research 15 507-514

Porter TD (1991) An unusual yet strongly conserved flavoprotein in bacteria and mammals Trends in Biochemical Science 16 154-158

Robertson KM, O'Donnell L, Jones ME, Meachem SJ, Boon WC, Fisher CR, Graves KH, McLachlan RI and Simpson ER (1999) Impairment of spermatogenesis in mice lacking a functional aromatase (cyp 19) gene Proceedings National Academy of Sciences USA 96 7986-7991

Roselli CE and Resko JA (1993) Aromatase activity in the rat brain: hormonal regulation and sex differences Journal of Steroid Biochemistry and Molecular Biology 44 499-508

Sanders SL and Stouffer RL (1997) Localization of steroidogenic enzymes in macaque luteal tissue during the menstrual cycle and simulated early pregnancy: immunohistochemical evidence supporting the two-cell model for estrogen production Biology of Reproduction 56 1077-1087

* Sasano H and Harada N (1998) Intratumoral aromatase in human 
breast, endometrial and ovarian malignancies Endocrine Reviews 19 593-607

Shetty G, Krishnamurthy H, Krishnamurthy N, Bhatnagar AS and Moudgal RN (1997) Effect of estrogen deprivation on the reproductive physiology of male and female primates Journal of Steroid Biochemistry and Molecular Biology 61 157-166

Siiteri PK (1982) Review of studies on estrogen biosynthesis in the human Cancer Research (Supplement) 42 3269s-3273s

Simpson ER (2000) Genetic mutations resulting in loss of aromatase activity in humans and mice Journal of the Society for Gynecological Investigation 7 S18-S21

Simpson ER and Zhao Y (1996) Estrogen biosynthesis in adipose. Significance in breast cancer development Annals of the New York Academy of Science 784 18-26

Simpson, ER, Mahendroo MS, Means GD et al. (1994) Aromatase cytochrome P450, the enzyme responsible for estrogen synthesis Endocrine Reviews 15 342-355

*Simpson ER, Zhao Y, Agarwal VR et al. (1997) Aromatase expression in health and disease Recent Progress in Hormone Research 52 185-213

Stratakis CA, Vottero A, Brodie A, Kirschner LS, DeAtkine D, Lu Q, Yue W, Mitsiades CS, Flor AW and Chrousos GP (1998) The aromatase excess syndrome is associated with feminization of both sexes and autosomal dominant transmission of aberrant P450 aromatase gene transcription Journal of Clinical Endocrinology and Metabolism 83 1348-1357

Swinney DC, Watson DM and So O-Y (1993) Accumulation of intermediates and isotopically sensitive enolization distinguish between aromatase (cytochrome P450 CYP19) from rat ovary and human placenta Archives of Biochemistry and Biophysics 305 61-67

Tanaka M, Fukuda S, Matsuyama M and Nagahama Y (1995) Structure and promoter analysis of the cytochrome P450 aromatase gene of the teleost fish, medaka (Oryzia latipes) Journal of Biochemistry (Tokyo) 117 719-725

Tchoudakova A and Callard GV (1998) Identification of multiple CYP19 genes encoding different cytochrome P450 aromatase isozymes in brain and ovary Endocrinology 139 2179-2189

Walters KW, Corbin CJ, Anderson GB, Roser JF and Conley AJ (2000) Tissue-specific localization of cytochrome P450 aromatase in the equine embryo by in situ hybridization and immunocytochemistry Biology of Reproduction 62 1141-1145

White PC (1994) Genetic diseases of steroid metabolism Vitamins and Hormones 49 131-195

Yoshida N and Osawa Y (1991) Purification of human placental aromatase cytochrome P450 with monoclonal antibody and its characterization Biochemistry 30 3003-3010

Zeitoun KM and Bulun SE (1999) Aromatase: a key molecule in the pathophysiology of endometriosis and a therapeutic target Fertility and Sterility 72 961-969

Zhang Y, Word A, Fesmire S, Carr BR and Rainey WE (1996) Human ovarian expression of 17ß-hydroxysteroid dehydrogenase types 1, 2 and 3 Journal of Clinical Endocrinology and Metabolism 81 3594-3598 